\title{
Musculoskeletal disorders in sign language interpreters: a systematic review protocol
}

Leandro Vieira Lisboa ( $\square$ leandrovieiralisboa@outlook.com )

Universidade Federal de Goias https://orcid.org/0000-0002-4334-2460

\section{Sara Ribeiro Nunes}

Universidade Federal de Goias

\section{Lorrane Caroline de Oliveira}

Universidade Federal de Goias

\section{Neuma Chaveiro}

Universidade Federal de Goias

\section{Dolors Rodríguez-Martín}

University of Barcelona: Universitat de Barcelona

\section{Protocol}

Keywords: Cumulative trauma disorders, interpreter, sign language, systematic review

Posted Date: December 7th, 2020

DOI: https://doi.org/10.21203/rs.3.rs-121899/v1

License: (c) (i) This work is licensed under a Creative Commons Attribution 4.0 International License. Read Full License 


\section{Abstract}

\section{Backgroud}

Full physical, mental and social well-being is presented by the World Health Organization (WHO) as a definition for health. The relationship between "health" and "work" is present in an area known as "worker health", this area aims to promote, protect, recover and rehabilitate workers' health. It is known that different musculoskeletal disorders affect employees from the most diverse occupational groups due to their working hours, with high cognitive and physical demands according to the specificity of each labor branch. The sign language interpreter is a professional who develops his activities by carrying out communication between users of two different languages, auditory-oral and visual-gestural, due to the high cognitive and physical demand of these professionals during simultaneous interpretation, there are risks of developing disorders musculoskeletal.

\section{Methods}

The study will be conducted by two independent reviewers following the rules of the Preferred Reporting Items for Systematic Reviews and Meta-Analyzes (PRISMA), a search will be carried out in the main databases: LILACS; SciELO; ScienceDirect; Scopus Elsevier; PubMED; Web of Science for the selection of articles published until 2020. There will be no language or locale limitations. The assessment of methodological quality will be carried out using instruments from the Joanna Briggs Institute (JBI).

\section{Discussion}

This systematic review aims to analyze the prevalence of musculoskeletal disorders in sign language interpreters from a systematic review.

\section{Systematic review registration}

PROSPERO, CRD42020178849

\section{Background}

The World Health Organization (WHO) from 1948 presented the concept of health as the full physical, mental and social well-being, and not the simple absence of disease as stated earlier [1]. The biological, social, cultural and environmental aspects are elements that make up health, which is achieved and preserved by each person in order to achieve all the characteristics presented in the concept of health by WHO [2].

The area of knowledge that seeks to understand the relationship between "work" and "health" is called worker health, which develops comprehensive health care for employees. Workers are exposed to various risks, organizational or environmental, according to their daily work activities [3]. Occupational health is related to the act of promoting and protecting individuals who dedicate their lives to develop some type 
of work activity, and working conditions can affect health impairment, especially if exercised without specific care in each area, for example, not using personal protective equipment. The health of the worker starts with prevention and his function continues in the recovery and rehabilitation of employees who are harmed due to their work activities [4].

Musculoskeletal disorders affect workers from the most diverse occupational groups, and can cause inflammation and degeneration, affecting mainly structures such as muscles, nerves, tendons, joints and cartilage, causing pain and functional limitation [5]. As a result of the significant burden of disability generated, these injuries cause a significant social and economic impact, represented by low quality of life for disabled workers, loss of productivity, lost work days, health care costs and social security compensation payments [6].

The sign language interpreter is the professional who develops his activities by carrying out communication between users of two different languages, an auditory-oral and a visual-gestural one, enabling communication between them [7]. When receiving the information in the source language, the interpreter must choose how to enunciate that information in the target language, expressing ideas and opinions, and even when there are no direct referents from one language to the other, being responsible for keeping the meaning as close as possible in the another language [8,9]. In this sense, the role played by the interpreter is outlined as a key point, since he is the link between the deaf and his "universe" that is mostly composed of listeners [10].

The sign language interpreter involves a high cognitive as well as physical demand due to simultaneous interpretation. Since these are movements with different speeds, repetitive and with uncomfortable positions, there are risks of developing musculoskeletal disorders, such as repetitive strain injuries (RSI) and work-related musculoskeletal disorders (WMSDS) [11].

\section{Objectives}

The objectives of this systematic review are:

1. Analyze the prevalence of musculoskeletal disorders in professional sign language interpreters.

2. Identifying the body region most affected with musculoskeletal disorders.

\section{Methods}

This is a systematic review of studies examining musculoskeletal disorders in sign language interpreters. The review was registered in the International Prospective Register of Systematic Reviews (PROSPERO) database [12] under registration number CRD42020178849. This protocol was structured according to the guidelines of the Preferred Report Items for Systematic Review and Meta-Analysis Protocols (PRISMAP) [13] (see Additional file 1). 
The guiding question of this study was: what is the prevalence of musculoskeletal disorders in sign language professionals due to their professional performance?

\section{Eligibility criteria}

The studies will be selected according to the criteria described below:

\section{Participants}

Studies with people of both sexes, with or without pathologies.

\section{Study designs}

Only observational studies that used generic or specific tools to assess the prevalence of musculoskeletal disorders in sign language interpreters should be included. Qualitative studies will be excluded.

\section{Interventions or exposure}

Professionals who act as sign language interpreters. Exclusion of professionals from other functions.

\section{Comparators}

Not applicable.

\section{Outcomes}

\section{Primary outcome}

The main outcome to be considered is the prevalence of different musculoskeletal disorders described in the studies according to the instruments used.

\section{Secondary outcomes}

Secondary results will not be considered in this review.

\section{Search methods}

The terms that will be used in the search were consulted in the Health Sciences Descriptors (DeCS) [14] and Medical Subject Headings (MeSH) [15],

Searches will be conducted in the following databases: Latin American and Caribbean Health Sciences Literature (LILACS) [16], Scientific Electronic Library Online (SciELO) [17], ScienceDirect [18], Scopus Elsevier [19], United States National Library of Medicine (PubMED) [20], Web of Science [21]. The search for the articles will take place in the year 2020 and no date filters and database languages will be used. 
The reference lists of the included articles will be analyzed to ensure studies that have not been found by searching the databases. For database searches, the following keywords or search terms will be used: "Cumulative Trauma Disorders" OR "Cumulative Trauma Disorder" OR "Disorder, Cumulative Trauma" OR "Disorder, Repetitive Motion" OR "Disorders, Cumulative Trauma" OR "Disorders, Repetitive Motion" OR "Injuries, Overuse" OR "Injuries, Repetition Strain" OR "Injuries, Repetitive Strain" OR "Injuries, Repetitive Stress" OR "Injury, Overuse" OR "Injury, Repetition Strain" OR "Injury, Repetitive Strain" OR "Injury, Repetitive Stress" OR "Motion Disorder, Repetitive" OR "Motion Disorders, Repetitive" OR "Overuse Injuries" OR "Overuse Injury" OR "Overuse Syndrome" OR "Overuse Syndromes" OR "Repetition Strain Injuries" OR "Repetition Strain Injury" OR "Repetitive Motion Disorder" OR "Repetitive Motion Disorders" OR "Repetitive Strain Injuries" OR "Repetitive Strain Injury" OR "Repetitive Stress Injuries" OR "Repetitive Stress Injury" OR "Strain Injuries, Repetition" OR "Strain Injuries, Repetitive" OR "Strain Injury, Repetition" OR "Strain Injury, Repetitive" OR "Stress Injuries, Repetitive" OR "Stress Injury, Repetitive" OR "Trauma Disorder, Cumulative" OR "Trauma Disorders, Cumulative" AND "sign language interpreter" OR "Interpreters" OR "Interpreter" OR "Sign Language Translator" OR "Translator". The data found in the search process will be organized in a Microsoft Excel spreadsheet.

\section{Selection of studies}

Two independent reviewers will conduct the search following three phases. After each phase, the authors will check the included and excluded studies and in case of disagreement the authors will analyze and decide on the studies' eligibility for review.

In phase 1 , the titles of the articles identified by the research will be selected according to the following criteria:

Is the study with sign language interpreters? (Yes, it is not clear or not)

Is it a study of musculoskeletal disorders? (Yes, it is not clear or not)

In phase 2, the abstracts of the studies selected in phase 1 will be read and selected according to the following criteria:

Is the study with sign language interpreters? (Yes, it is not clear or not)

Is it a study of musculoskeletal disorders? (Yes, it is not clear or not)

Is it an observational study? (Yes, it is not clear or not)

Does the study use any instrument for the analysis of musculoskeletal disorders? (Yes, it is not clear or not)

In phase 3 , the studies will be read in full and a table will be drawn up with the following information: 
Country of origin

Study title

Year of publication of the study

Objective of the study

Analysis tool

Sample Number

\section{Main Results}

Assessment of study risk bias

Immediately after filling in the information related to phase 3, the authors will present the reasons for exclusion from the studies and thus register in text for later consultation. None of the authors of this review will be blind to the titles of the journals or authors or institutions of study. A study flowchart will be made containing measures, such as identification, screening, eligibility and inclusion of items with quantities, and an explanation of the reason for exclusion.

Additional information from the authors of the included studies will be requested to resolve questions about study eligibility.

\section{Data extraction and management}

Using a detailed step-by-step, reviewers will be able to extract studies from the databases independently following the same "path" and organize them in Excel software spreadsheets. The summarized data will include the name of the authors of the studies, title of the journal, date of publication; country of origin of the studies; the assessment tools for musculoskeletal disorders of the participants; socioeconomic profile of sign language interpreters; methodology; details of intervention and results. In case of possible differences found in the assessment tools for musculoskeletal disorders, they will be analyzed by grouping equal or similar parts of the instruments. The reviewers will resolve any differences. In case of lack of information, the reviewers will contact the authors of the studies that were included in this review via email.

\section{Quality assessment}

The evaluation of the methodological quality of the articles will be carried out with instruments from the Joanna Briggs Institute (JBI) [22], according to the design of the selected study.

The classification of the studies will be identified as: "low risk of bias" when more than $80 \%$ of the established criteria are reached; "Medium risk of bias" when the criteria fulfilled are between $50 \%$ to $80 \%$ 
and "high risk of bias" when less than $50 \%$ of the criteria are reached according to the instrument used.

\section{Evidence synthesis}

A systematic narrative synthesis will be provided with information presented in the selected studies using tables to summarize and explain the characteristics and results of the included studies (authors; country; title; year of publication; objective; sample; instrument; result).

\section{Dissemination}

The results of this review will be submitted in a journal of the same theme, and from the peer review the results will be reported according to the items in the Preferred Reporting Items for Systematic Reviews and Meta-Analyzes (PRISMA) [23]. A flow chart will be used to show the selection of articles with the reasons for exclusion. The characteristics of the study and the results will be presented in summary tables. The current protocol follows the rules of PRISMA-P [13].

The results will also be disseminated to the research community and key stakeholders through presentations at relevant academic and non-academic meetings and through social media.

\section{Discussion}

We hope that this study will contribute to the discussion and creation of public policies as an insertion of protective means in the work environments of professional sign language interpreters for the prevention of IHR and WMSDS. Discuss the importance of having a specific time for continuous interpretation and subsequent rest, or having more than one professional acting with alternate substitution for physical and mental recovery and avoiding musculoskeletal disorders.

The research will be part of a master's thesis, articles, posters and discussions that may instigate further research on this theme. This systematic review may have limitations, for example, the exclusion of works not published in scientific journals or presented at scientific events.

\section{Abbreviations}

DeCs: Health Sciences Descriptors

JBI: Joanna Briggs Institute

LILACS: Latin American and Caribbean Literature in Health Sciences

MeSH: Medical Subject Headings

PRISMA: Preferred Reporting Items for Systematic Reviews and Meta-Analyzes

PRISMA-P: Preferred Reporting Items for Systematic Review and Meta-Analysis Protocols 
PROSPERO: International Prospective Register of Systematic Reviews

PubMEd: United States National Library of Medicine

RSI: Repetitive strain injury

SciELO: Scientific Electronic Library Online

SCOPUS: ELSEVIER database

UL: Upper limbs

WHO: World Organization of Health

WMSDS: work-related musculoskeletal disorders

\section{Declarations}

\section{Funding}

This study will be funded by the authors.

\section{Ethics approval and consent to participate}

Not applicable.

\section{Consent for publication}

Not applicable.

\section{Availability of data and materials}

Data sharing does not apply to this protocol, as no data sets were analyzed yet.

\section{Competing interests}

The authors declare that they have no conflicting interests.

\section{Funding}

This study will be financed by the authors themselves. Non-financial sources include the provision of library and database by Universidade Federal de Goiás in Goiânia, Goiás, Brazil.

\section{Authors' contributions}

LVL, SRN and LCO developed the protocol, the search strategy, the manuscript and the record of the systematic review. NC contributed to the design of the research and protocol questions, critically reviewed 
and provided comments on the manuscript drafts and agreed with the final version sent. DRM critically reviewed and provided comments on the draft manuscript and agreed with the final version submitted. All authors read, provided feedback and approved the final manuscript.

\section{Acknowledgements}

Not applicable

\section{Authors' information}

Faculdade de Medicina. Programa Ciências da Saúde, Universidade Federal de Goiás, secretaria-1a s/nSetor Universitário, Goiânia, Goiás, 74605-020, Brazil

Leandro Vieira Lisboa, Sara Ribeiro Nunes, Lorrane Caroline de Oliveira \& Chaveiro Nunes

Escola d'Infermeria de la Facultad de Medicina i Ciències de la Salut de la Universitat de Barcelona. Carrer de Casanova, 143, 08036 Barcelona, Espanha.

Dolors Rodríguez-Martín

\section{References}

1. Organización Mundial de la Salud. Constituciónde la Organización Mundial de la Salud, 2006 https://www.who.int/governance/eb/who_constitution_sp.pdf. Accessed 09 september 2020.

2. SCLIAR M. História do conceito de saúde. Physis. 2007; 17(1):29-41. doi: https://doi.org/10.1590/S0103-73312007000100003.

3. JUNIOR JRV. Fisioterapia do Trabalho: Cuidando da Saúde Funcional do Trabalhador. São Paulo: Andreoli, 2014.

4. Shiri R, Kausto J, Martimo KP, Kaila-Kangas L, Takala EP, Viikari-Juntura E, Health-related effects of early part-time sick leave due to musculoskeletal disorders: a randomized controlled trial., Scand J Work Environ Health, 2013, 39(1):37-45, doi: http://dx.doi.org/10.5271/sjweh.3301.

5. Haeffner R, Kalinke LP, Felli VEA, Mantovani MF, Consonni D, Sarquis LMM. Absenteeism due to musculoskeletal disorders in Brazilian workers: thousands days missed at work. Rev. bras. epidemiol. 2018; 21:e180003. doi: https://doi.org/10.1590/1980-549720180003.

6. Souza NSS, Santana VS. Incidência cumulativa anual de doenças musculoesqueléticas incapacitantes relacionadas ao trabalho em uma área urbana do Brasil. Cad. Saúde Pública. 2011; 27(11):2124-2134. doi: https://doi.org/10.1590/S0102-311X2011001100006.

7. WITCHS PH, LOPES MC. Deaf's way of life and its cultural markers. Educ. rev. 2018; 34:e184713. doi: http://dx.doi.org/10.1590/0102-4698184713.

8. ALBRES NA, RODRIGUES CH. The Roles of the Educational Interpreter: Between Social Practicesand Education Policies. Bakhtiniana: Rev. Estud. Discurso. 2018; 13(3):15-41. doi: 
https://doi.org/10.1590/2176-457335335.

9. SANTOS KAS, LACERDA CBF. Libras-Portuguese Interpreter in the Context of Conferences:Reflections on Their Work. Bakhtiniana: Rev. Estud. Discurso. 2018; 13(3):63-82. doi: http://dx.doi.org/10.1590/2176-457335404.

10. SILVA CM, SILVA DS, MONTEIRO R, SILVA DNH. Inclusão Escolar: Concepções dos Profissionais da Escola sobre o Surdo e a Surdez. Psicol. cienc. prof. 2018; 38(3):465-479. doi: http://dx.doi.org/10.1590/1982-37030002652017.

11. WOODCOCK K, FISCHER SL. Occupational health and safety for sign language interpreters. Toronto: Ryerson University, 2008. http://www.avlic.ca/docs/OHSGuideforSLI.pdf. Accessed 09 september 2020.

12. PROSPERO-International prospective register of systematic reviews http://www.crd.york.ac.uk/PROSPERO/. Accessed 09 september 2020.

13. Shamseer L, Moher D, Clarke M, Ghersi D, Liberati A, Petticrew M, Shekelle P, Stewart LA. Preferred reporting items for systematic review and meta-analysis protocols (PRISMA-P) 2015: elaboration and explanation. BMJ. 2014; 10.1136/bmj.g7647.

14. DeCS - Descritores em Ciências da Saúde http://decs.bvs.br/. Accessed 09 september 2020.

15. MeSH - Medical Subject Headings https://www.ncbi.nlm.nih.gov/mesh/. Accessed 09 september 2020.

16. Literatura Latino-Americana e do Caribe em Ciências da Saúde (LILACS). https://lilacs.bvsalud.org. Accessed 09 september 2020.

17. Scientific Electronic Library Online (SCIELO). https://scielo.org/php/index.php. Accessed 09 september 2020.

18. ScienceDirect. https://www.sciencedirect.com. Accessed 09 september 2020.

19. Scopus Elsevier. https://www.elsevier.com. Accessed 09 september 2020.

20. United States National Library of Medicine (PubMED). https://pubmed.ncbi.nlm.nih.gov. Accessed 09 september 2020.

21. Web of Science. https://www.webofknowledge.com. Accessed 09 september 2020.

22. The Joanna Briggs Institute. The Joanna Briggs Institute Critical Appraisal tools, 2017 https://joannabriggs.org/critical-appraisal-tools. Accessed 09 september 2020.

23. Moher D, Liberati A, Tetzlaff J, Altman DG; PRISMA Group. Preferred reporting items for systematic reviews and meta-Analyses: the PRISMA Statement. PLoS Med. 2009; 6(7): e1000097.

\section{Supplementary Files}

This is a list of supplementary files associated with this preprint. Click to download.

- PRISMAP2015Checklist.doc 
- PRISMAP2015Checklist.doc 